\title{
OS LUSÍADAS NA TRADUÇÃO DE WILLIAM JULIUS MICKLE: A REENCENAÇÃO DE UMA TRANSLATIO STUDII ET IMPERII
}

\author{
WILLIAM JULIUS MICKLE'S TRANSLATION OF OS LUSÍADAS: \\ A RE-ENACTMENT OF A TRANSLATIO STUDII ET IMPERII
}

\section{Cláudia Santana Martins*}

\section{RESUMO}

The Lusiad; or, The Discovery of India, a tradução de Os lusíadas de Camões feita pelo poeta escocês William Julius Mickle, publicada na Inglaterra em 1776, fez sucesso em sua época e no século que se seguiu, sendo até hoje a mais lida e citada entre todas as traduções poéticas de Os lusíadas para o inglês. Este artigo procura demonstrar que a tradução de Mickle (e os elementos paratextuais que a acompanham) é uma reencenação da teoria medieval da translatio studii et imperii (a transferência não apenas do poder imperial, mas também do conhecimento e da cultura do leste para o oeste). Mickle adaptou a epopeia camoniana para o público britânico do final do século XVIII, rotulou-a como "A Epopeia do Comércio" e acrescentou paratextos de cunho ideológico. Manipulando o poema original tanto poética quanto ideologicamente, Mickle transformou Os lusíadas em uma narrativa a serviço do Império Britânico e contribuiu, como outros "poetas do comércio" que celebraram o crescimento da riqueza e poder da Grã-Bretanha, para forjar uma identidade poética e cultural para o Império Britânico.

Palavras-chave: tradução e ideologia; manipulação; Estudos da Tradução.

\section{ABSTRACT}

The Lusiad; or, The Discovery of India, the translation of Camões's Os lusiadas by the Scottish poet William Julius Mickle, published in Oxford in 1776, was a success in its time and in the ensuing century, and is to this day the most widely read and quoted among all the poetic translations of Os lusíadas into English. This paper aims to demonstrate that Mickle's translation (and the paratextual elements added to it) is a re-enactment of the medieval theory of translatio studii et imperii (the transfer not only of imperial power, but also of knowledge and culture from East to West). Mickle adapted Camões's epic for the late eighteenth-century British audience, labelled it as "The Epic Poem of Commerce" and added ideologically charged paratexts. By manipulating the original poem both poetically and ideologically, Mickle transformed Os lusiadas into a narrative at the service of the British Empire and contributed, as other "poets of commerce" who celebrated the growth of Britain's wealth and power, to forge a poetic and cultural identity for the British Empire.

Keywords: translation and ideology; manipulation; Translation Studies.

\footnotetext{
* USP, São Paulo (SP), Brasil. clam@uol.com.br

http://dx.doi.org/10.1590/0103-18134579161981
} 


\section{INTRODUÇÃO}

The Lusiad, or, The Discovery of India, a tradução do poema Os lusíadas, de Luís Vaz de Camões, feita pelo poeta escocês William Julius Mickle e publicada na Inglaterra em 1776, obteve muito sucesso quando de sua publicação e no século que a ela se seguiu. Os mil exemplares da primeira edição foram rapidamente vendidos e uma segunda edição foi lançada dois anos depois. Ao todo, essas duas edições renderam ao tradutor cerca de mil libras, uma quantia apreciável na época. A popularidade dessa tradução nos séculos XVIII e XIX pode ser comprovada por suas sucessivas reedições na Grã-Bretanha: nove edições foram publicadas em pouco mais de um século, entre 1776 e 1877. Até hoje, é a mais lida e citada de todas as traduções poéticas da obra para o inglês. ${ }^{1}$ (FERREIRA, 1992a, p. 65; 1992b, p. 70; ESTORNINHO, 1960, p. 153).

Este artigo pretende mostrar que a tradução de Mickle recorre a uma reencenação e atualização da teoria medieval da translatio imperii et studii (a transferência do poder e da cultura), adaptando o épico camoniano ao público britânico do final do século XVIII. Mickle acrescentou paratextos de cunho ideológico e rotulou o poema como "A Epopeia do Comércio". Manipulando o poema original tanto no aspecto poético quanto ideológico, o tradutor transformou Os lusíadas em uma narrativa em apoio aos interesses imperialistas da Grã-Bretanha.

\section{TRANSLATIO STUDII ET IMPERII}

A translatio studii et imperii é um conceito de origem medieval, segundo o qual, em analogia com o movimento do sol, haveria uma transmissão de leste para oeste não só do controle imperial, mas também da cultura e do conhecimento. A civilização, surgida no Oriente Próximo, teria sido gradualmente transferida para a Grécia e depois para Roma. Curtius (1996, p. 62) comenta que a ideia da sucessão de um império por outro encontrava sustentação na Bíblia - no Eclesiástico 10:8 ("O poder passa de uma nação para outra por causa da injustiça, da violência e das riquezas") ${ }^{2} \mathrm{e}$

1 Existem onze traduções completas de Os lusíadas para a língua inglesa. A de Mickle foi a segunda. A primeira foi feita por Sir Richard Fanshawe, em 1655. A tradução de Fanshawe circulou apenas entre um grupo restrito de intelectuais, caindo em seguida no esquecimento, mas foi reabilitada no século XX, ganhando duas novas edições, uma de Geoffrey Bullough (1963) e outra de Peter Davidson (1998). (FERREIRA, 1992a, pp. 64-65; 1992b, p. 70; RAMOS, LOUSADA, 1992, pp. 9-11).

2 Tradução extraída do sítio Bíblia Católica Online. Disponível em: < http://www.bibliacatolica.com. br/24/28/10.php\#.URpm4h1mVa4 >. Acesso em 12 fev. 2013. 
em Daniel 2:21 ("Ele muda os tempos e as estações; ele remove os reis e estabelece os reis; é ele quem dá a sabedoria aos sábios e o entendimento aos entendidos") ${ }^{3}$. Essas passagens eram usadas na Europa medieval para fundamentar a translatio imperii, ou seja, a ascensão e queda dos impérios e as mudanças de domínio político. A legitimidade do Império de Carlos Magno foi justificada exatamente com base na ideia de translatio: o Império Romano estaria sendo transferido para o Império Carolíngio.

Na história contada no livro de Daniel (2:29-49), Nabucodonosor sonhou com uma grande estátua, de cabeça de ouro, peito e braços de prata, ventre e coxas de bronze, pernas de ferro e pés parcialmente de ferro e parcialmente de barro. Enquanto Daniel admirava a escultura, uma enorme pedra caiu do alto, acertando os pés da estátua e destruindo-a. A pedra cresceu até se transformar em uma montanha e cobrir toda a Terra. Na interpretação de Daniel, o rei seria a cabeça de ouro, e as outras partes da estátua seriam diferentes impérios que se sucederiam no controle e domínio do mundo. Posteriormente, pensadores cristãos como Santo Agostinho, São Tomás de Aquino e Lutero, deram uma interpretação mais historicista ao sonho: a cabeça de ouro seria o Império Babilônico; o peito e os braços de prata, o Império Medo-Persa; o ventre e as coxas de bronze, a Grécia Helenística; as pernas de ferro seriam o Império Romano, e os pés de ferro e barro denotariam o Império Romano dividido (Há várias outras interpretações, com maiores ou menores discrepâncias em relação a essa que é a mais frequente no final da Idade Média.)

O historiador medievalista Jacques Le Goff (1990, pp. 305-306) observa que esse relato de Daniel introduz uma contagem mítica do tempo histórico que alcança grande repercussão, possibilitando uma "tentativa de periodização 'política' da história e, ao mesmo tempo, um esboço de descrição e interpretação da evolução histórica, do ponto de vista político e cultural". A concepção de que a história desloca os centros de poder para o oeste será uma das fontes da ideologia ocidental e acentuará "o isolamento da civilização cristã pela rejeição às civilizações contemporâneas, a bizantina, a muçulmana, as asiáticas"4 (LE GOFF, 2008, p. 145). Outro aspecto dessa teoria - mencionado por Haywood (2009) - é que ela é a imagem de uma transmissão unidirecional, em que o poder e a cultura são transferidos sem alterações.

A tradução, obviamente, desempenhou um papel primordial na translatio studii. O próprio termo translatio, em latim, significava ao mesmo tempo "tradução"

3 Tradução extraída do sítio Bíblia Online. Disponível em: < http://www.bibliaonline.com.br/ aa+acf/ $\mathrm{dn} / 2>$. Acesso em 12 fev. 2013.

4 "l'isolement de la civilisation chrétienne en rejetant les civilisations contemporaines, la byzantine, la musulmane, les asiatiques". 
e "transferência". ${ }^{5}$ Foi por meio de traduções que os romanos se apropriaram da riqueza cultural da Grécia. Na Idade Média, esse processo de apropriação teve continuidade - a cultura pagã dos gregos e romanos precisou ser adequada aos padrões cristãos medievais. O latim escrito se transformou em língua franca na Europa medieval - a língua em que se escreviam os textos científicos, jurídicos e religiosos. O latim vulgar, por sua vez, deu origem às línguas vernáculas europeias. Por volta do século IX, as diferenças entre o latim clássico e o vulgar já eram tão acentuadas que a própria Igreja e a realeza passaram a autorizar as traduções para o vernáculo - que, por sua vez, contribuíram para a maturação e a padronização das línguas vernáculas.

A teoria da translatio studii et imperii foi usada frequentemente ao longo da história para justificar as pretensões imperialistas de um país, povo, soberano ou agrupamento político. Os clássicos (e, especialmente, as epopeias) foram constantemente retraduzidos, adaptados e imitados, retornando muitas vezes, sob novas roupagens, para dar sustentação a cada novo império, e muitos artistas e intelectuais cumpriram a função de propagadores (hoje diríamos "propagandistas") dessa nova ordem - a translatio studii acompanha sempre a translatio imperii. (KERMODE, 1983)

\section{OS LUSÍADAS E A TRANSLATIO STUDII ET IMPERII}

O poema Os lusíadas é considerado não apenas a grande epopeia nacional portuguesa, mas uma das principais epopeias da Idade Moderna, junto com a Jerusalém libertada, de Torquato Tasso, e O Paraíso perdido, de John Milton. O tema é a história de Portugal - desde as origens míticas (a fundação da Lusitânia por Luso, filho ou companheiro do deus Baco, e as narrativas sobre o pastor Viriato) até as Grandes Navegações -, relatada a partir de vários acontecimentos que se desenvolvem durante a viagem de Vasco da Gama às Índias. Os lusíadas são uma obra de alcance enciclopédico, refletindo as concepções geográficas, históricas e sociais de seu tempo e da Antiguidade. Pelo fato de expressarem a visão de mundo de sua época com tanta lucidez, abrangência e profundidade, Os lusíadas assumiram um lugar de destaque na cultura universal.

A teoria da translatio studii et imperii - que associamos a Portugal mais comumente no contexto seiscentista da doutrina messiânica do Quinto Império, do Padre

\footnotetext{
5 A palavra traductio não existia em latim, tendo surgido apenas quando as línguas vernáculas já estavam se estabelecendo. O primeiro a usá-la foi Leonardo Bruni, baseando-se, segundo Berman (1988, p. 30), no particípio passado traductum empregado pelo autor latino Aulo Gélio. Para Gélio, porém, traductum não significava "traduzido", e sim "transportado".
} 
Antônio Vieira - foi utilizada, junto com outras teorias messiânicas, por D. Manuel I, para fundamentar as suas pretensões imperialistas. ${ }^{6} \mathrm{O}$ historiador lusitano Luís Filipe Thomaz (2008, p. 100) interpreta o projeto imperial de D. Manuel como "uma espécie de grande síntese de todos os projetos de cruzada, mitos, aspirações e utopias do outono da Idade Média", cuja novidade estava na fusão entre os aspectos messiânicos medievais e a estratégia universalista moderna.

Embora o sucessor de D. Manuel, D. João III, não abraçasse as mesmas estratégias do pai, as ambições imperialistas e o espírito cruzadístico continuaram bem vivos em Portugal durante seu reinado.

Os lusíadas refletem claramente essas influências, a ponto de podermos considerá-los uma encenação da teoria da translatio studii et imperii. Camões utiliza a Eneida de Virgílio como modelo a orientar a translatio, adotando as virtudes da ética romana e transferindo para Portugal várias marcas distintivas atribuídas a Roma.

Já na proposição, o Poeta enuncia a sua intenção de, conforme os preceitos clássicos, superar seus modelos no campo literário (o "sábio Grego" indica Homero, e o "Troiano" é Eneias, o protagonista da Eneida) e, no mesmo passo, declara Portugal o sucessor, na história, da Antiguidade Clássica (representada por Alexandre e Trajano):

Cessem do sábio Grego e do Troiano

As navegações grandes que fizeram;

Cale-se de Alexandro e de Trajano

A fama das vitórias que tiveram

Que eu canto o peito ilustre Lusitano $[\ldots](\mathrm{I}, 3)^{7}$

O Consílio dos Deuses, em seguida, imita a matriz virgiliana. Porém, enquanto na Eneida Júpiter faz uma longa profecia sobre o destino dos romanos, n’Os lusíadas Júpiter discorre sobre a sucessão de impérios (Assírios, Persas, Gregos e Romanos) e declara Portugal o futuro império mundial:

"Se do grande valor da forte gente

De Luso não perdeis o pensamento,

Deveis de ter sabido claramente

6 O título assumido por D. Manuel desde a volta de Vasco da Gama da Índia, "Senhor da conquista, navegação e comércio da Etiópia, Arábia, Pérsia e Índia", anuncia as pretensões imperialistas do rei. É interessante também a observação de Thomaz (2008, p. 45), de que "esta é a primeira e talvez a única vez que um soberano inclui a atividade comercial em seus títulos reais".

7 As citações de Os lusíadas são extraídas da edição organizada pelo Dr. Álvaro Júlio da Costa Pimpão (CAMÕES, 2000). 
Como é dos Fados grandes certo intento

Que por ela se esqueçam os humanos

De Assírios, Persas, Gregos e Romanos." (I, 24)

No Canto II, estrofes 44 a 46, Júpiter o reafirma:

"Que eu vos prometo, filha, que vejais

Esquecerem-se Gregos e Romanos,

Pelos ilustres feitos que esta gente

Há-de fazer nas partes do Oriente [...]

E por eles, de tudo enfim senhores,

Serão dadas na terra leis milhores."

Outro prognóstico da glória futura de Portugal imitado da Eneida é o sonho de D. Manuel. Na Eneida (Livro VIII), o rio Tibre aparece em sonhos a Eneias, anunciando as grandes realizações que levarão à fundação de Roma; n'Os lusíadas (Canto IV), D. Manuel sonha com os rios Indo e Ganges, que, assumindo a forma de dois anciãos, antecipam-lhe que as terras por eles banhadas serão conquistadas pelos portugueses.

"Ó tu, a cujos reinos e coroa

Grande parte do mundo está guardada,

Nós outros, cuja fama tanto voa,

Cuja cerviz bem nunca foi domada,

Te avisamos que é tempo que já mandes

A receber de nós tributos grandes." (IV, 73)

Até mesmo Baco, o inimigo, sabe que esse é o destino dos portugueses decidido por um poder superior ao dos deuses pagãos:

Via estar todo o Céu determinado

De fazer de Lisboa nova Roma;

Não no pode estorvar, que destinado

Está doutro Poder que tudo doma. (VI, 7)

Esse destino já se evidencia desde o início da história de Portugal como relatada por Paulo da Gama: o primeiro rei, Afonso Henriques, é tão amado por Deus e tão heroico que por ele "no Estígio lago jura a Fama / De mais não celebrar nenhum de Roma" (VIII, 11). 
Poderíamos citar muitos outros exemplos, mas os já citados nos parecem suficientes para concluirmos que Camões se valeu do código épico a fim de construir uma identidade imperial para Portugal a partir do modelo clássico de Virgílio. Os lusíadas são, portanto, um instrumento de legitimação histórica e a encenação de uma translatio studii et imperii: uma obra que exalta as façanhas do Império Português, que estaria destinado a ultrapassar os feitos dos impérios anteriores, e declara a si própria como a expressão máxima dos conhecimentos alcançados por esse Império.

\section{A GRÃ-BRETANHA SETECENTISTA}

No final do século XVIII, a Grã-Bretanha, um império construído com base no comércio e expandido pelas armas, vivia uma fase de extraordinário crescimento econômico e o início da Revolução Industrial. As vitórias na Guerra da Sucessão Espanhola (1702-1713) e na Guerra dos Sete Anos (1756-1763) causaram impacto, demonstrando o novo poderio militar do país e assinalando o início de uma hegemonia britânica na Europa.

Em termos culturais, é um momento de transição entre o Neoclassicismo da época augustana e o Romantismo, quando, embora a influência clássica ainda estivesse presente, diversos elementos chamados por alguns estudiosos de "préromânticos" começavam a se evidenciar.

Outro aspecto cultural importante desse momento histórico é que os escritores e poetas deixam de depender apenas da aristocracia e passam à esfera de influência pública, burguesa. Surgem os cafés literários, onde se reúne um novo público, anônimo, que assina periódicos e debate as questões da atualidade. A transição da cultura aristocrática para a comercial e da economia patronal para a de mercado não foi, contudo, rápida nem completa. Os editores/livreiros [booksellers] ganharam poder econômico e cultural, mas não suplantaram o sistema de patronagem aristocrática - que continuou exercendo forte controle sobre a cultura e a política (CARPEAUX, 1961, pp. 1.297-1.298; GRIFFIN, 2006, p. 10).

A tradução, especialmente a de obras clássicas, ainda era encarada como uma atividade importante - os poetas augustanos buscavam revitalizar a cultura nacional seguindo os modelos clássicos greco-latinos (MILTON, 1998, p. 25). Os tradutores se sentiam autorizados a "aperfeiçoar" o original a fim de restituir o "espírito", a "ideia" do autor. O que se considerava prioritário ao se traduzir um texto de uma língua para outra não era a palavra e, muitas vezes, nem mesmo o sentido, mas os 
elementos retóricos, a "eloquência", efeitos estéticos e emocionais do texto, que era, assim, reencenado na tradução.

As ideias de translatio studii et imperii eram centrais para a historiografia e a poesia britânica setecentistas. A poesia transformou-se em veículo privilegiado para a exaltação dos ideais mercantis do Império Britânico em expansão (KAUL, 2000; 2009). Sob o paradigma da translatio studii et imperii, os poetas desenvolveram vários topoi. "As armas e as artes", o comércio e a liberdade eram enaltecidos como virtudes que distinguiam a Grã-Bretanha dos demais países. Profetizava-se que Londres seria a "Nova Roma" e que o Império Britânico em expansão seria o novo Império Romano. Assim como o Império Romano justificava a sua dominação com base nos benefícios da Pax Romana, também o domínio britânico traria, segundo esses poetas, paz ao mundo, graças às leis britânicas, que promoviam a liberdade - e esta, pelo mito da translatio libertatis, seria transferida às colônias britânicas (SHIELDS, 1990, p. 16).

A teoria da translatio fornecia aos poetas setecentistas britânicos um modelo extremamente adequado, pois, ao projetar uma sucessão de leste para oeste e da Antiguidade para o presente, amparava as próprias pretensões imperialistas da GrãBretanha e conferia às novas simbologias imperiais uma autoridade que se originava da Antiguidade que os neoclássicos tanto prezavam.

\section{O LUSIAD DE MICKLE}

O escocês William Julius Mickle, segundo tradutor de Os lusíadas para o inglês, foi um desses poetas que contribuíram para forjar uma identidade imperial para a Grã-Bretanha. Nascido em 1735, em Langholm, Escócia, mudou-se para Londres em 1762 para tentar ganhar a vida como poeta e escritor. Acrescentou a seu nome de nascença, "William Meikle", o segundo nome, "Julius", talvez para melhor se adequar às preferências neoclássicas ainda vigentes, e alterou a grafia do sobrenome (de Meikle para Mickle) para ocultar as origens escocesas. Enfrentou muitas dificuldades para obter patronagem, mas conseguiu um emprego de revisor na Clarendon Press, em Oxford, e veio a integrar o círculo literário do célebre Samuel Johnson (REED, 1789; IRELAND, 1794 e SIM, 1809).

$\mathrm{O}$ ambicioso projeto de traduzir Os lusíadas - poema que havia encantado Mickle já aos 17 anos, na tradução francesa em prosa de Duperron de Castera era mais uma tentativa de alcançar a fama e o sucesso financeiro. Mickle deu à tradução o título de The Lusiad. O subtítulo escolhido, The Discovery of India, revela o 
enfoque eurocêntrico, pois, quando os portugueses chegaram à região que viria a ser denominada Índia, já viviam ali povos civilizados há pelo menos quatro milênios povos que já haviam, inclusive, passado por processos de unificação, o primeiro dos quais ocorrido durante o Império Máuria (322 a.C.-185 a.C.). É evidente também que o tradutor procura dirigir a atenção do leitor para a viagem de Vasco da Gama, em detrimento de outros temas desenvolvidos no épico camoniano, em virtude da importância que esse tema apresenta para a história do comércio e do Império Britânico. Mickle acrescenta ainda um rótulo bastante sugestivo: para o tradutor, Os lusíadas serão "a Epopeia do Comércio", assim como O Paraíso perdido era "a Epopeia da Religião".

A tradução foi publicada com o patrocínio de uma lista de quase 600 pessoas influentes do mundo intelectual, religioso e político. Entre elas, vários membros da Companhia das Índias Orientais - uma companhia poderosíssima naqueles tempos, pois, além de controlar todo o comércio entre a Grã-Bretanha e a Ásia, governou a Índia em nome da Coroa britânica entre 1757 e 1858, tendo até mesmo um exército próprio. Na época da publicação do Lusiad de Mickle, o papel da Companhia das Índias Orientais na Ásia estava sendo questionado - não apenas em relação ao monopólio, criticado pelos defensores do livre-comércio, como Adam Smith, mas também quanto à capacidade de uma companhia comercial administrar, sem o apoio direto da Coroa, regiões tão distantes da metrópole. As denúncias de casos de crimes, corrupção e despotismo cometidos por membros da Companhia se avolumavam. (GREENE, 2001, pp. 222-229; BOWEN, 2001, pp. 530-551; ROBINS, 2006, p. 89).

Com muita habilidade, Mickle montou um verdadeiro "pacote" para vender o seu produto, acrescentando à tradução diversos elementos paratextuais: uma longa introdução (publicada em 167 páginas, sem subdivisões, na primeira edição, e ampliada na segunda edição para 236 páginas, sendo então subdividida em diversos títulos) e cerca de setecentas notas explicativas, algumas bastante extensas. A introdução contém uma refutação à tese do "bom selvagem" e uma entusiástica defesa da expansão ultramarina; uma história do descobrimento da Índia; uma história da ascensão e queda do Império Português no Oriente; uma biografia encomiástica de Camões; uma dissertação sobre Os lusíadas e a poesia épica; uma dissertação sobre a "máquina" 8 da Jerusalém de Tasso e da Henriade de Voltaire e uma dissertação sobre a ficção da Ilha dos Amores. ${ }^{9}$ Esses elementos paratextuais foram

$8 \mathrm{O}$ uso da mitologia pagã.

$9 \mathrm{Na}$ segunda edição, Mickle acrescentou uma dissertação sobre os princípios religiosos e a filosofia dos brâmanes. 
acrescentados pelo tradutor não só para apresentar, situar, elucidar e valorizar o original de Camões e a sua tradução, mas também para reforçar a interpretação de que Os lusíadas são "A Epopeia do Comércio" e, dessa forma, apoiar as iniciativas de comércio, colonização e expansão marítima do Império Britânico; além de defender o monopólio da Companhia das Índias Orientais (que era uma das patrocinadoras da tradução).

\section{O LUSIAD COMO REENCENAÇÃO DE UMA TRANSLATIO}

Para reencenar, em sua tradução, a translatio encenada n'Os lusíadas e, assim, apropriar-se da epopeia camoniana em nome do Império Britânico, o tradutor recorreu a vários artifícios, tanto de ordem ideológica quanto poética. ${ }^{10}$ Entre os recursos de ordem ideológica de que o tradutor se valeu para operar uma intervenção política no texto original encontram-se:

1. A transferência para o Império Britânico de várias características dos heróis e da nação portugueses retratados por Camões e a apropriação desses heróis e de suas façanhas para a defesa do comércio e da expansão marítima. Em certos trechos, o tradutor chega a efetuar uma translatio da translatio camoniana.

2. A introdução de referências elogiosas ao comércio.

3. A defesa do militarismo e do expansionismo.

4. A acentuação do enfoque etnocêntrico já presente no original. O tradutor descreve os povos nativos da África e da Ásia como primitivos ou selvagens, e enfatiza a "missão" europeia de civilizá-los.

Concomitantemente, Mickle adaptou o poema camoniano ao gosto poético predominante na época na Grã-Bretanha - com um sucesso atestado pelas várias reedições da obra nos séculos XVIII e XIX. Os principais recursos empregados pelo tradutor nessa remodelagem foram:

1. Retratar a natureza em estilo pré-romântico.

2. Enfatizar os elementos sublimes.

3. Intensificar, sempre que possível, a emotividade do poema.

4. Eliminar várias alusões mitológicas a fim de tornar o poema mais fluente.

10 Seguimos, aqui, os conceitos de Bassnett e Lefevere (1992: vii-viii), para quem toda tradução reflete uma ideologia e uma poética, sendo, como tal, manipulação exercida a serviço do poder. 
5. Atenuar ou eliminar as digressões camonianas, que - segundo a visão neoclássica - enfraqueciam o efeito épico do poema.

6. Remover ou cristianizar as passagens eróticas que pudessem ofender a sensibilidade dos cavalheiros e damas britânicos do século XVIII.

Não será possível, no âmbito deste artigo, fornecermos exemplos de todos os artifícios citados acima. Apresentaremos apenas alguns exemplos de alguns desses artifícios. Como a tradução de Mickle difere muito do original, retraduziremos os trechos citados para o português, de forma propositalmente literal, em notas de rodapé.

\subsection{Glorificação do comércio}

Entre a tradução das estrofes 36 e 37 do Canto VII, durante a descrição que o mouro Monçaide faz do samorim e dos habitantes da região, Mickle enxerta uma série de versos em louvor ao comércio em Calecute sem nenhuma contrapartida no original:

And soon to Calicut's commodious port

The fleets, deep-edging with the wave, resort:

Wide o'er the shore extend the warlike piles,

And all the landscape round luxurious smiles.

And now her flag to every gale unfurl'd,

She towers the Empress of the eastern world:

Such are the blessings sapient kings bestow,

And from thy stream such gifts, O Commerce, flow. ${ }^{11}$

(CAMÕES, 1776a, p. 290).

No Canto VII, na estrofe 62, em que Vasco da Gama propõe ao samorim um pacto de paz, amizade e intercâmbio comercial, Mickle amplifica a referência ao comércio com três versos de elogios efusivos (salientados em itálico no quadro a seguir):

11 E logo ao confortável porto de Calecute

As esquadras, em contato profundo com as ondas, recorrem:

Amplamente sobre a praia estendem as lanças de guerra,

E toda a paisagem ao redor sorri, exuberante.

E agora sua bandeira é desfraldada para todos os ventos,

Ela se eleva sobre a Imperatriz do mundo oriental:

Tais são as dádivas que os reis sábios concedem,

E de teu rio tais presentes, oh Comércio, fluem. 


\begin{tabular}{|l|l|}
\hline \multicolumn{1}{|c|}{ Original (canto VII, estrofe 62) } & \multicolumn{1}{c|}{ Tradução (1776, p. 308) } \\
\hline E se queres, com pactos e lianças & \\
De paz e de amizade, sacra e nua & Pleased thy high grandeur and renown to hear, \\
Comércio consentir das abondanças & My Sovereign offers friendship's bands sincere: \\
Das fazendas da terra sua e tua, & Mutual he asks them, naked of disguise, \\
Por que cresçam as rendas e abastanças & Then every bounty of the smiling skies \\
(Por quem a gente mais trabalha e sua) & Shower'd on bis shore and thine, in mutual flow, \\
De vossos Reinos, será certamente & Shall joyful Commerce on each shore bestow. ${ }^{12}$ \\
De ti proveito, e dele glória ingente. & \\
\hline
\end{tabular}

O tradutor glorifica o comércio, fonte de dádivas ("every bounty", "shower' $\mathrm{d}$ ", "on each shore bestow") e alegrias ("smiling skies", "joyful Commerce"). O original menciona "abondanças", crescimento das rendas, "abastanças" e "proveito", porém o enfoque dado pelo tradutor é mais positivo, ainda mais se considerarmos que Mickle omite a distinção estabelecida pelo original entre os "ganhos" a serem auferidos pelo governante de Calecute e pelo rei de Portugal ("de ti proveito e dele glória ingente" $)$, reunindo todos indistintamente em uma celebração ao comércio ("mutual he asks them" e "in mutual flow"). ${ }^{13}$

\subsection{Acentuação do Enfoque Etnocêntrico}

Os lusíadas de Camões expressam a visão cristã e aristocrática que era hegemônica em sua época - uma visão que hoje em dia qualificaríamos como etnocêntrica, pois interpreta o mundo da perspectiva de seu próprio grupo, mostrando-se incapaz de entender outros grupos e culturas que adotem valores diferentes dos seus. Assim, enquanto os portugueses são glorificados por seus valores cristãos e civilizados, os povos nativos são descritos como "Cafres, ásperos e avaros" (Canto V, 47); "Cafres selvagens" (X, 38), "selvática gente, negra e nua"

12 Satisfeito de saber de tua alta nobreza e renome,

Meu Soberano oferece laços de amizade sincera:

Mútuos ele os requisita, sem disfarces,

Então todas as dádivas dos céus risonbos

Derramadas sobre as terras dele e tuas, em fluxo mútuo,

$\mathrm{O}$ alegre Comércio em ambas as terras fornecerá.

13 Mickle só traduz o verso "De ti proveito, e dele glória ingente" várias linhas depois, após o conteúdo da estrofe seguinte, que se refere à oferta de apoio bélico. Esse deslocamento faz com que a distinção estabelecida no original entre os "ganhos" a serem auferidos pelo governante de Calecute e pelo rei de Portugal ("de ti proveito" / "dele glória ingente") perca a força e o comércio seja apresentado como algo de benefício mútuo. A tradução de Mickle: "The glory his, the gainful harvest thine" ["A glória será dele; a proveitosa ceifa, tua"]. 
(X, 93). Já aos "mouros"14 é concedida uma identidade cultural, mas apenas como os tradicionais inimigos da fé cristã. Recebem, em consequência, uma adjetivação que denota, quase sempre, falsidade e maldade: "falso Mouro" (I, 72; I, 99); "bruta gente" capaz de "vil malícia, pérfida, inimiga" (I, 92); "malina gente" (I, 99; VIII, 58); "infidas gentes" (II, 1); "infiel e falsa gente" (II, 6); "pérfida, inimiga e falsa gente" (II, 30); "os Perros" (III, 48), "o povo imundo" (VII, 2); seguidores do "falso Mahamede" (II, 50); o "Profeta falso e noto" (VIII, 47).

Por seu turno, a visão de Mickle dos habitantes da África e da Ásia é, geralmente, a de povos primitivos que podem evoluir e civilizar-se pelo contato com os europeus. Essa visão é claramente expressa nos peritextos do Lusiad e se reflete na própria tradução. Ao se referir aos "mouros", Mickle tende a ser menos depreciativo do que Camões - o tradutor preza a tolerância religiosa, ainda mais quando esta favorece o comércio. Ao se referir a outros povos africanos e asiáticos, no entanto, o tradutor muitas vezes acentua o etnocentrismo do original por meio de amplificações que detalham o estado primitivo e "bárbaro" desses povos.

Como exemplo, citaremos a tradução da segunda estrofe do Canto I, em que Mickle inclui quatro versos (destacados abaixo em itálico) que não apresentam uma correspondência exata no original, explicitando e detalhando a menção presente no original a "terras viciosas" e à dilatação da Fé:

\begin{tabular}{|l|l|}
\hline \multicolumn{1}{|c|}{ Original (canto I, estrofe 2) } & \multicolumn{1}{c|}{ Tradução (pp. 2-3) } \\
\hline & Vent'rous I sing, on soaring pinions borne, \\
E também as memórias gloriosas & And all my Country's wars the song adorn, \\
Daqueles Reis que foram dilatando & What Kings, what Heroes of my native land \\
A Fé, o Império, e as terras viciosas & Thunder'd on Asia's and on Afric's strand: \\
De África e de Ásia andaram devastando, & Illustrious shades, who levell'd in the dust \\
E aqueles que por obras valerosas & The idol-temples and the shrines of lust: \\
Se vão da lei da Morte libertando, & And where, erewbile, foul demons were rever'd, \\
Cantando espalharei por toda parte, & To Holy Faith unnumber'd altars rear'd: \\
Se a tanto me ajudar o engenho e arte. & Illustrious names, with deathless laurels crown'd, \\
& While time rolls on in every clime renown'd! ${ }^{15}$ \\
\hline
\end{tabular}

14 A palavra vem de "mauro", habitante da Mauritânia, e era inicialmente aplicada aos árabes-bérberes do Norte da África e na Península Ibérica, mas foi depois estendida a todos aqueles que professavam a fé islâmica (hoje chamados de islamitas, muçulmanos ou maometanos).

15 Ousado eu canto, sustentado em asas ascendentes,

E todas as guerras do meu país o canto adornam;

Os Reis, os Heróis de minha terra natal

Proclamados na costa da Ásia e da Àfrica:

Ilustres espíritos, que reduziram a pó 
Mickle menciona especificamente a destruição dos templos dedicados a ídolos e santuários "da luxúria" ("The idol-temples and the shrines of lust"), onde eram cultuados "demônios repugnantes" ("foul demons"), e a construção de altares cristãos. Dessa forma, o tradutor amplifica a exaltação aos valores cristãos e o menosprezo às religiões africanas e asiáticas já presentes no original.

Ao traduzir a estrofe 92 do Canto X, Mickle introduz a sua própria visão da situação da África. Enquanto o original diz apenas "Inculta e toda cheia de bruteza", Mickle se estende, descrevendo a falta de cultivo das terras ("Her lands uncultured", "neglected fields"), a falsidade ("her sons untrue"), brutalidade ("Savage and fierce they roam in brutal strife") e falta de refinamento cultural dos africanos ("Ungraced with all that sweetens human life"; "naked"):

\begin{tabular}{|l|l|}
\hline \multicolumn{1}{|c|}{ Original (canto X, estrofe 92) } & \multicolumn{1}{c|}{ Tradução (pp. 449-450) } \\
\hline "Vês Europa Cristã, mais alta e clara & Here Christian Europe lifts the regal head. \\
Que as outras em polícia e fortaleza. & Afric behold, alas, what alter'd view! \\
Vês África, dos bens do mundo avara, & Her lands uncultured, and her sons untrue; \\
Inculta e toda cheia de bruteza; & Ungraced with all that sweetens human life, \\
Co Cabo que até 'qui se vos negara, & Savage and fierce they roam in brutal strife; \\
Que assentou pera o Austro a Natureza. & Eager they grasp the gifts which culture yields, \\
Olha essa terra toda, que se habita & Yet naked roam their own neglected fields. ${ }^{16}$ \\
Dessa gente sem Lei, quási infinita." & \\
\hline
\end{tabular}

\subsection{Natureza retratada em estilo pré-romântico}

Ao traduzir a estrofe 52 do Canto IX, quando se inicia o episódio da Ilha dos Amores, Mickle insere vários elementos descritivos ressaltando cores e brilhos ("green bosom of the dewy lawn"; "Soft blazing"; "silver of the dawn"; "glowing lustre") e um verso que alude aos perfumes da Arábia ("Arabia’s balm was sprinkled

Os templos idólatras e os santuários da luxúria:

E onde, pouco tempo atrás, demônios repugnantes eram reverenciados,

À Santa Fé inúmeros altares ergueram:

Ilustres nomes, com louros imortais coroados,

Enquanto o tempo passa, celebrizados em todas as partes!

16 Aqui a Europa Cristã ergue a sua cabeça régia.

Vede a África, ai, que visão diferente!

Suas terras incultivadas e seus filhos desleais;

Desprovidos de tudo o que adoça a vida humana,

Selvagens e ferozes eles perambulam em conflitos brutais;

Ávidos agarram as dádivas que o cultivo produz,

Mas andam nus por seus campos abandonados. 
o'er the air") - um elemento exótico, para os padrões europeus - a fim de ampliar os efeitos sinestésicos do poema:

\begin{tabular}{|c|c|}
\hline Original (canto IX, estrofe 52 ) & Tradução (1776, pp. 385) \\
\hline De longe a Ilha viram, fresca e bela, & O'er the green bosom of the dewy lawn \\
\hline Que Vénus pelas ondas lha levava & Soft blazing flow'd the silver of the dawn, \\
\hline (Bem como o vento leva branca vela) & The gentle waves the glowing lustre share, \\
\hline Pera onde a forte armada se enxergava; & Arabia's balm was sprinkled o'er the air. \\
\hline Que, por que não passassem, sem que nela & Before the fleet, to catch the heroes' view, \\
\hline Tomassem porto, como desejava, & The floating isle fair Acidalia drew: \\
\hline Pera onde as naus navegam a movia & Soon as the floating verdure caught their sight, \\
\hline A Acidália, que tudo, enfim, podia. & She fixt, unmov'd, the island of delight. ${ }^{17}$ \\
\hline
\end{tabular}

$\mathrm{Na}$ tradução do episódio da Ilha dos Amores, Mickle preserva as referências clássicas de Camões, mas, como bem observa Monica Letzring (1965, pp. 40-41), acrescenta carvalhos e cedros às árvores mencionadas e evoca as regiões campestres britânicas incluindo também duas variedades de prímulas ["primrose" e "cowslip"], assim como morangos ["scarlet strawberries"] e "cordeiros brancos como leite" ["milk white lambs"]. ${ }^{18} \mathrm{O}$ carvalho e o cedros são acrescentados na tradução das estrofes 57 e 58, em que Mickle adiciona diversos elementos sinestésicos ao original ${ }^{19}$ :

17 Sobre o seio verde do campo orvalhado

Resplandecendo suave afluiu a prata da aurora,

As ondas gentis compartilham o brilho incandescente,

O bálsamo da Arábia estava pulverizado no ar.

Para a frente da esquadra, a fim de atrair a atenção dos heróis,

A ilha flutuante a bela Acidália arrastou:

Assim que avistaram o verde flutuante,

Ela fixou, imóvel, a ilha do prazer.

18 Além disso, segundo Letzing (1965, pp. 41), a cena descrita por Mickle (CAMÕES, 1776, pp. 397) das ninfas nas águas se baseia no episódio da "Morada da Felicidade" ["Bower of Bliss"] da Faerie Queene de Spenser.

19 Este exemplo já foi citado em Martins (2013). 


\begin{tabular}{|l|l|}
\hline \multicolumn{1}{|c|}{ Original (canto IX, estrofe 57) } & \multicolumn{1}{|c|}{ Tradução (1776, pp. 388-389) } \\
\hline & Wild forest-trees the mountain sides array'd \\
& With curling foliage and romantic shade: \\
& Here spreads the poplar, to Alcides dear; \\
As árvores agrestes, que os outeiros & And dear to Phobus, ever verdant here, \\
Têm com frondente coma enobrecidos, & The laurel joins the bowers for ever green, \\
Álemos são de Alcides, e os loureiros & The myrtle bowers belov'd of beauty's queen. \\
Do louro Deus amados e queridos $;$ & To Jove the oak his wide-spread branches rears; \\
Mirtos de Citereia, cos pinheiros & And high to heaven the fragrant cedar bears; \\
De Cibele, por outro amor vencidos; $;$ & Where through the glades appear the cavern'd rocks, \\
Está apontando o agudo cipariso & The lofty pine-tree waves her sable locks; \\
Pera onde é posto o etéreo Paraíso. & Sacred to Cybelle the whispering pine \\
& Loves the wild grottoes where the white cliffs shine; \\
& Here towers the cypress, preacher to the wise, \\
& Less'ning from earth her spiral honours rise, \\
& Till, as a spear-point rear'd, at the topmost spray; \\
& Points to the Eden of eternal day. ${ }^{20}$ \\
\hline
\end{tabular}

Além de agregar uma adjetivação que acentua impressões sensoriais e emocionais associadas à natureza (wild forest trees; romantic shade; verdant; fragrant cedar; whispering pine; wild grottoes), o tradutor efetua uma amplificação, acrescentando vários versos.

Os outros elementos da paisagem britânica que mencionamos acima (as prímulas, os morangos e o cordeiro) são acrescentados em uma passagem sem correspondência no original, após a tradução da estrofe 62 do Canto IX:

20 Árvores da floresta agreste se enfileiravam nas encostas da montanha

Com folhas enroladas e uma sombra romanesca:

Aqui se espalha o álamo, caro a Alcides;

E caro a Febo, sempre verdejante aqui,

O loureiro se junta aos caramanchões sempre verdes,

Os caramanchões de mirto amados pela rainha da beleza.

Para Júpiter o carvalho ergue seus ramos bem abertos;

E alto ao céu o cedro perfumado se dirige;

Onde nas clareiras aparecem rochedos cavernosos,

O imponente pinheiro agita seus cachos negros;

Sagrado para Cibele o pinheiro sussurrante

Ama as grutas selvagens onde os penhascos brancos brilham;

Aqui se eleva o cipreste, pregando aos sábios,

Diminuindo a partir da terra, seus ornamentos espirais ergue,

Até que, como a ponta de uma lança hasteada, no ramo mais alto;

Aponta para o Éden do dia eterno. 
Where by the stream the lilly of the vale,

Primrose, and cowslip meek, perfume the gale,

Beneath the lilly and the cowslip's bell

The scarlet strawberries luxurious swell. ${ }^{21}$

(CAMÕES, 1776, p. 393).

\subsection{Translatio da translatio camoniana}

No Canto VII do original, as estrofes de 50 a 54 descrevem painéis desenhados e esculpidos nas paredes do palácio do samorim, representando cenas da Antiguidade. A estrofe 54 alude à Terceira Monarquia, de Alexandre, o Grande, que sucedeu ao Império dos Assírios e dos Persas. Na sequência dessa evocação à teoria da sucessão dos impérios, nas estrofes 55 e 56, o catual lembra as profecias dos sábios magos sobre a futura dominação da Índia por "gentes estrangeiras". A interpretação é clara: temos aqui uma referência auspiciosa ao Quinto Império dos portugueses. As qualidades desse império são resumidas assim no original:

Mas também diz que a bélica excelência,

Nas armas e na paz, da gente estranha

Será tal, que será no mundo ouvido

$\mathrm{O}$ vencedor por glória do vencido.

(VII, 56)

A tradução de Mickle especifica os atributos do domínio português de maneira um tanto diferente:

But swift behind these wintery days of woe

A spring of joy arose in liveliest glow,

Such gentle manners leagued with wisdom reign'd

In the dread victors, and their rage restrain'd.

Beneath their sway majestic, wise, and mild,

Proud of her victors' laws thrice happier India smiled. ${ }^{22}$

(CAMÕES, 1776, p. 306).

21 Onde junto ao regato o lírio-do-vale,

E as tímidas prímulas perfumam a brisa,

Sob o lírio e a campânula da prímula

Os morangos escarlates crescem exuberantes.

22 Mas logo depois desses dias hibernais de angústia

Uma fonte de alegria surgiu com o brilho mais vívido,

Tais maneiras gentis associadas à sabedoria reinavam

Nos temíveis vencedores, e sua raiva contida.

Sob o seu domínio majestoso, sábio e brando,

Orgulhosa das leis de seu vencedor, três vezes mais feliz, a Índia sorriu. 
Vemos, nesses versos, que Mickle atribui aos futuros vencedores não apenas o poder e a capacidade de inspirar medo e respeito ("dread victors"; "sway majestic"), mas também a gentileza ("gentle manners"); a sabedoria ("wisdom"; "wise"); o controle da ira ("their rage restrain'd"); e a temperança ("mild"). Todas essas virtudes fariam que os dominados se alegrassem com a sua condição de dominados ("A spring of joy arose in liveliest glow"; "Proud of her victors" laws thrice happier India smiled"). Essa seria uma boa síntese do imperialismo "paternalista" defendido por Mickle - e também a síntese da própria ideologia do imperialismo britânico.

Para interpretar a tradução desse trecho, é importante observar que na Introdução do Lusiad de Mickle já anunciara a transferência dessa profecia - que no original se referia aos portugueses - para os britânicos, que sucederam os portugueses na Índia. Reproduziremos aqui - na versão da segunda edição do Lusiad, em que esse trecho foi ampliado - a passagem em que Mickle introduz a citação dessa profecia de Camões:

A superioridade das artes civis e militares dos britânicos, não obstante o caráter odioso de alguns indivíduos, é atualmente contemplada na Índia com todo o assombro de admiração; e admiração é sempre seguida, ainda que muitas vezes em passos atrasados, pelo forte desejo se uma melhoria semelhante. Muito tempo depois da queda do Império Romano, as leis romanas foram adotadas por povos que Roma Antiga considerava bárbaros. E assim, no decorrer de eras, as leis britânicas, segundo todas as probabilidades, produzirão um efeito da maior importância: cumprirão a profecia de Camões e transferirão para os britânicos o grande cumprimento que ele presta a seus compatriotas [...] $]^{23}$ (MICKLE, 1778, p. xi).

O uso da translatio studii et imperii é claro aqui: assim como houve a passagem do domínio do Império Romano para as nações europeias, o domínio dos portugueses na Índia se transfere para os britânicos, e da mesma forma que os indianos se beneficiaram com o domínio português, beneficiar-se-ão com o domínio britânico. Implicitamente, nessa transferência do império, Camões e Mickle desempenham o papel de agentes da transferência da cultura e do conhecimento (translatio studii).

23 The superiority of the civil and military arts of the British, notwithstanding the hateful character of some individuals, is at this day beheld in India with all the astonishment of admiration; and admiration is always followed, though often with retarded steps, by the strong desire of similar improvement. Long after the fall of the Roman empire the Roman laws were adopted by nations which ancient Rome esteemed as barbarous. And thus, in the course of ages, the British laws, according to every test of probability, will have a most important effect, will fulfil the prophecy of Camoens, and transfer to the British the high compliment he pays to his countrymen $[\ldots]$ 


\subsection{Apropriação dos heróis portugueses e adequação ao modelo épico}

O herói da epopeia de Camões é o povo português. Isso já se evidencia no título ("Os lusíadas" designa os portugueses ${ }^{24}$ ) e na proposição (estrofes 1 a 3), em que é declarado o assunto do poema. O Poeta se propõe a cantar "as armas e os barões assinalados" que se aventuraram por territórios desconhecidos e edificaram novos reinos (estrofe 1); assim como "as memórias gloriosas" dos reis e dos heróis que dilataram o império e a fé (estrofe 2). O verso 21 sintetiza a exposição do assunto do poema nas três estrofes iniciais: "[Que] eu canto o peito ilustre Lusitano".

$\mathrm{Na}$ tradução de Mickle, diferentemente do que acontece no original, Vasco da Gama é o herói. Isso fica bem claro já na terceira estrofe do Canto I, quando Mickle traduz "Que eu canto o peito ilustre Lusitano" como "A nobler hero's deeds demand my lays / Than e'er adorn'd the song of ancient days, / Illustrious GAMA, whom the waves obey'd, / And whose dread sword the fate of empire sway'd.". A grafia do nome "Gama" com as letras em versalete se mantém ao longo de toda a tradução, destacando o nome do herói.

\begin{tabular}{|l|l|}
\hline \multicolumn{1}{|c|}{ Original (canto l, estrofe 3) } & \multicolumn{1}{c|}{ Tradução (pp. 3-4) } \\
\hline & Let Fame with wonder name the Greek no more, \\
Cessem do sábio Grego e do Troiano & What lands he saw, what toils at sea he bore ${ }_{i}$ \\
As navegações grandes que fizeram, & Nor more the Trojan's wandering voyage boast, \\
Cale-se de Alexandro e de Trajano & What storms he brav'd, how driven on many a coast: \\
A fama das vitórias que tiveram, & No more let Rome exult in Trajan's name, \\
Que eu canto o peito ilustre Lusitano, & Nor Eastern conquests Ammon's pride proclaim, \\
A quem Neptuno e Marte obedeceram. & A nobler hero's deeds demand my lays \\
Cesse tudo o que a Musa antiga canta, & Than e'er adorn'd the song of ancient days, \\
Que outro valor mais alto se alevanta. & Illustrious GAMA, whom the waves obey'd, \\
& And whose dread sword the fate of empire sway'd. ${ }^{25}$ \\
\hline
\end{tabular}

24 A palavra "lusíadas" foi um neologismo criado pelo humanista André de Resende no poema Carmen eruditum et elegans Angeli Andreae Resendii Lusitani, aduersus stolidos politioris litteraturae oblatratores, mais tarde intitulado Erasmi Encomium, publicado em 1531. É uma forma derivada da palavra Lusus [Luso] mediante o sufixo iades [descendente], conforme o modelo de Virgílio: Aenead, ae, -um [descendentes de Eneias, Eneiadas].

Camões foi o primeiro a empregar a palavra em português. (PEREIRA, 2011, pp. 489-490.)

25 Que a Fama não mencione mais o grego com admiração,

As terras que viu, as dificuldades por que passou no mar;

Nem exalte a viagem errante do troiano,

As tempestades que enfrentou, as muitas costas que percorreu:

Que Roma não mais exalte o nome de Trajano,

Nem os conquistadores do Oriente proclamem o orgulho de Amon;

Exigem meus cantos as façanhas de um herói mais nobre

Do que os outros que adornaram o canto dos dias de outrora

O Ilustre GAMA, a quem as ondas obedeciam

E cuja espada temida influenciou o destino do império. 
A decisão de Mickle de se concentrar em Vasco da Gama se explica tanto por fatores ideológicos quanto poéticos. Ideologicamente, Vasco da Gama simbolizava muito bem os ideais de expansão marítima e comercial. Quanto à poética, a questão é que, segundo a maioria dos teóricos neoclássicos, os padrões do gênero exigiam que um poema épico apresentasse apenas um herói. Assim, do início ao fim de sua tradução, Mickle se empenhou em distinguir e enaltecer a figura de Vasco da Gama.

Na apresentação do Gama (acima) já se evidenciam algumas das características do herói de Mickle: fama ("illustrious"), capacidade de liderança e de impor sua vontade ("whom the waves obey'd / And whose dread sword the fate of empire sway'd").

O último exemplo que apresentaremos se refere àquele que talvez seja o maior "escândalo" da tradução de Mickle de Os lusíadas - um exemplo que contém omissões, acréscimos, amplificações e outros tipos de modificação. ${ }^{26}$ No final do Canto VIII, Mickle suprimiu totalmente 19 das últimas 24 estrofes, conservando o conteúdo das outras cinco apenas em parte, reaproveitando-o de modo resumido e em contexto alterado, e acrescentou 53 versos inteiramente de sua criação; na sequência, no início do Canto IX, Mickle eliminou 11 das primeiras 15 estrofes, traduziu quatro parcialmente em outro contexto e adicionou 308 versos de sua lavra. Todas essas alterações foram feitas para reescrever a narrativa do original sobre o episódio da disputa entre Vasco da Gama e o samorim de Calecute. Vejamos, então, quais são as diferentes histórias contadas pelo original e pela tradução. (FERREIRA, 1992b, p. 78; SOUTHEY, 1822, p. 32; TAYLOR, 1937, p. 162).

No original, Camões procura, aparentemente, seguir as fontes históricas: o samorim de Calecute impediu os portugueses de voltarem para suas naus com as mercadorias que haviam obtido por meio de trocas com os comerciantes locais. Em represália, Vasco da Gama mandou aprisionar alguns comerciantes de Calecute que chegaram às naus portuguesas para vender pedras preciosas. Com isso, obteve um acordo, pelo qual os portugueses seriam autorizados a voltar às suas naus e Vasco da Gama libertaria os prisioneiros. Os portugueses voltaram, de fato, às naus, mas Gama não libertou todos os comerciantes: levou alguns consigo como prisioneiros, descumprindo o acordo. ${ }^{27}$

26 Este exemplo já foi citado em Martins (2013).

27 O poema original diz que Gama libertou apenas alguns dos reféns, mas afirma também que os malabares levados por Gama a Lisboa teriam sido aprisionados quando, por ordem do samorim, chegaram às naus portuguesas acompanhando os feitores que estavam sendo devolvidos. Esse último relato, segundo Pimpão (CAMÕES, 2000, p. 414, notas), contradiz o depoimento do cronista Castanheda, para quem os malabares levados a Portugal fariam parte do grupo de comerciantes aprisionados. 
A história contada por Mickle na tradução é diferente: Vasco da Gama foi feito prisioneiro pelo samorim de Calecute, que exigia que as naus dos portugueses aportassem e se entregassem. Vasco da Gama rejeitou terminantemente. Em reação, o samorim mandou atacar as naus portuguesas. Na batalha que se seguiu, houve uma violenta tempestade, e toda a frota do samorim foi destruída. Os portugueses bombardearam Calecute, e o samorim pediu rendição.

Nesse episódio da disputa entre Gama e o samorim, Mickle precisou alterar radicalmente o original para que a imagem de seu herói não ficasse conspurcada. Afinal, fazer uma barganha com o inimigo e depois não manter a palavra não são gestos heroicos ou dignificantes... Era necessário elevar a figura de seu herói para que se adequasse aos padrões atribuídos ao gênero épico no século XVIII. É interessante observar, no entanto, que o gesto de bombardear toda uma cidade em represália a um ataque às naus portuguesas é, para o tradutor britânico, compatível com o de um herói épico. (FERREIRA, 1992b, p. 78; SOUTHEY, 1822, p. 32; TAYLOR, 1937, p. 162).

\section{CONCLUSÃO}

Os exemplos analisados, referentes tanto aos paratextos do Lusiad quanto à própria tradução, demonstram que o poeta escocês William Julius Mickle se apropriou da epopeia lusitana e, traduzindo-a, transformou-a na "Epopeia do Comércio", um poema em louvor à expansão marítima e em defesa da Companhia das Índias Orientais (uma das patrocinadoras da tradução). Ao fazê-lo, seguiu a tendência de grande parte dos poetas britânicos do século XVIII, que utilizaram modelos retóricos para forjar um mito nacional, uma identidade poética e cultural para o Império Britânico. Podemos dizer, portanto, que Mickle reencenou a translatio camoniana, atualizando-a para o Império Britânico da segunda metade do século XVIII.

\section{REFERÊNCIAS BIBLIOGRÁFICAS}

BASSNETT, S.; LEFEVERE, A. (1992). General Editor's Preface. In: Lefevere, A. Translation, Rewriting and the Manipulation of the Literary Fame. London: Routledge, pp. vii-viii.

BERMAN, A. (1988). De la translation à la traduction. TTR: traduction, terminologie, rédaction, vol. $1, \mathrm{n}^{\circ} 1$, pp. 23-40. 
BOWEN, H. V. (2001) British India, 1765-1813: The Metropolitan Context. In MARSHALL, P. J. (ed). The Oxford History of the British Empire. Vol. 2. The eighteenthcentury. New York: Oxford University Press, pp. 530-551.

CAMÕES, L. V. (1776). The Lusiad; or, the discovery of India. Translated by William Julius Mickle. London, Oxford: Jackson and Lister.

CAMÕES, L. V. (1778). The Lusiad; or, the discovery of India. Translated by William Julius Mickle. London, Oxford: Jackson and Lister, 2nd edition.

CAMÕES, L. V. Os lusíadas. (2000). Prefácio e Notas de Álvaro Júlio da Costa Pimpão. Lisboa: Ministério dos Negócios Estrangeiros. Instituto Camões.

CARPEAUX, O. M. (1961). História da literatura ocidental. Vol. 3. Rio de Janeiro: O Cruzeiro. CURTIUS, E. R. (1996). Literatura européia e idade média latina. São Paulo: HUCITEC/ EDUSP. ESTORNINHO, C. (1960). O culto de Camões em Inglaterra. Arquivo de Bibliografia Portuguesa, Coimbra, 6, pp. 152-169.

FERREIRA, I. S. (1992a). Apontamento biográfico relativo aos tradutores de Os lusíadas. In: Souza, M. L. M. (coord.). Camões em Inglaterra. Lisboa: Ministério da Educação. Instituto de Cultura e Língua Portuguesa, pp. 64-69.

FERREIRA, I. S. (1992b). Uma leitura de Os lusíadas: William Julius Mickle. In: Souza, M. L.

M. (coord.). Camões em Inglaterra. Lisboa: Ministério da Educação. Instituto de Cultura e Língua Portuguesa, pp. 70-95.

GREENE, J. P. (2001) Empire and Identity from the Glorious Revolution to the American Revolution. In MARSHALL, P. J. (ed). The Oxford History of the BritishEmpire. Vol 2. The eighteenth-century. New York: Oxford University Press, pp. 208-232.

GRIFFIN, D. H. (2006). Literary Patronage in England, 1650-1800. Cambridge: Cambridge University Press.

HAYWOOD, L; MONTGOMERY, J. E. (2009). Al-Andalus and España: Translatio and Tolerance. Mellon Teaching Seminar Series. CRAASH Lent Term. Disponível em: $<$ http://www.crassh.cam.ac.uk/uploads/documents/session2.pdf > Acesso em: 25 dez. 2013.

IRELAND, J. (1794). Life of the Author. In: Mickle, W. J. Poems, and a Tragedy. London: Printed by A. Paris for J. Egerton et al, pp. xi-lii.

KAUL, S. (2009). Eighteenth-century British Literature and Postcolonial Studies. Edinburgh: Edinburgh University Press.

KAUL, S. (2000). Poems of Nation, Anthems of Empire: English Verse in the Long Eighteenth Century. Virginia: The University Press of Virginia.

KERMODE, F. (1983). The Classic: literary images of permanence and change. Cambridge, Mass: Harvard University Press.

LE GOFF, J. (1990). História e memória. Tradução de Bernardo Leitão et al. Campinas: Editora da UNICAMP.

LE GOFF, J. (2008). La civilisation del'occident médiéval. Col. Champs histoire. Paris: Flammarion. 
LETZRING, M. (1964, 1965 e 1971). The Influence of Camoens in English Literature. Revista Camoniana, vols. I-III, São Paulo, pp. 158-180, 27-54, 57-134.

MARTINS, C.S. (2013). A "Epopeia do Comércio". Os lusíadas no Império Britânico do século XVIII. Tradução \& Comunicação: Revista Brasileira de Tradutores, v. 26, p. 21-36.

MICKLE, W. J. (1778) Introduction, dissertations, and appendix. In: Camões, L. The Lusiad, or, the discovery of India. Translated by William Julius Mickle. London, Oxford: Jackson and Lister: i-ccxxxvi, 2nd edition.

MILTON, J. (1998). Tradução: teoria e prática. São Paulo: Martins Fontes.

PEREIRA, V. S. (2001). Lusíadas. In: Dicionário de Luís de Camões. São Paulo: LeYa, 2011, pp. 489-490.

RAMOS, I. F.; LOUSADA, I. C. (1992). Traduções de Os lusíadas em Inglaterra. In: Souza, M. L. M. (coord.). Camões em Inglaterra. Lisboa: Ministério da Educação/Instituto de Cultura e Língua Portuguesa, pp. 9-63.

REED, I. (1789). An Account of the Life and Writings of William Julius Mickle. In European Magazine. London, Vol. 16, Sept. 1789, pp. 155-157; Nov. 1789, pp. 317-321.

ROBINS, N. (2006). The corporation that changed the world: how the East India Company shaped the modern multinational. London: Pluto Press.

SHIELDS, D. (1990). Oracles of Empire: poetry, politics, and commerce in British America, 1690-1750. Chicago: The University of Chicago Press.

SIM, Rev. J. (1809). New Life of the Author. In MICKLE, W. J. The poetical works of William Julius Mickle. London: J. Barfield, pp. ix-lxiv.

SOUTHEY, R. (1822). Memoirs of the Life and Writings of Luis de Camoens. By John Adamson F. S. A. The Quarterly Review. London, Vol. XXVII, n. LIII, pp. 1-39, April 1822.

TAYLOR, E. (1937). William Julius Mickle (1734-1788): A Critical Study. Washington, D.C.: Catholic University of America.

THOMAZ, L. F. (2008). A idéia imperial manuelina. In: Doré, A.; Lima, L. F. S.; Silva, L. G. (orgs.). Facetas do império na bistória: conceitos e métodos. São Paulo: Hucitec.

Enviado: 20/01/2015

Recebido: $15 / 03 / 2015$ 